\title{
Mechanism of Silver Nanoparticles Deposition by Electrolysis and Electroless Methods on a Graphite Substrate
}

\section{Prof. Dr. Mahmoud A. Rabah*}

Chemical and electrochemical treatment Lab. Mineral Processing Dept., Central metallurgical Research and Development Institute (CMRDI), El-Flezzat Str. El-Tebbin, Cairo, Egypt.

$$
\underline{0000-0002-1609-4203}
$$

Email: $\underline{\text { mrabah010@gmail.com }}$

\section{Prof. Dr. Nabil Nassif Girgis}

Control and Surface Protection Lab, Central metallurgical Research and Development Institute (CMRDI), El-Flezzat Str. El-Tebbin, Cairo, Egypt

Email: nabilnassif01@ hotmail.com

\begin{abstract}
This study shows a silver electrodeposition model (EDM) on a graphite substrate. The electrolyte was a $0.01 \mathrm{M}$ solution of pure silver and chromium nitrate using an electrolyzing cell. EDC with current density up to $20 \mathrm{~mA} / \mathrm{cm}^{2}$ and $15 \mathrm{mV}$ and pulse current were studied. Results revealed that silver deposited at a rate of $0.515 \mathrm{mg} / \mathrm{cm}^{2} / \mathrm{min}$ with $12 \mathrm{~mA} / \mathrm{cm}^{2}$ that decreases to 0.21 and 0.16 $\mathrm{mg} / \mathrm{cm}^{2}$.min with the decrease of current density to 6 and $5 \mathrm{~mA} / \mathrm{cm}^{2}$ respectively. The model postulates that silver ions (a) were first hydrated before diffusing (b) from the solution bulk to the cathode vicinity, the next step (c) involved the chemical adsorption of these ions on certain accessible sites of the graphite substrate (anode), the discharged entities (d) adhere to the graphite surface by Van der Vales force. Silver ions are deposited because the discharge potential of silver is low $(0.38 \mathrm{mV})$ as compared to other metal ions like chromium $(0.82 \mathrm{mV})$. Pulse current controls silver deposition due to flexibility in controlling steps (a) - (c) of the deposition mechanisms.
\end{abstract}


Parameters like current density, current on-time, current-off time, duty cycle (ratio of current on time and total pulse time) and pulse frequency influenced the shape and size of the deposits. Step (b) suggested that silver particles were deposited in a monolayer thickness. The silver layer turned multiple after fully satisfying the accessible sites with the monolayer. The activation energy $\Delta E$ value amounts to $86.32 \mathrm{~kJ} / \mathrm{mol} / \mathrm{K}$. At high temperature and current density, homogeneous diffusion occurs.

Keywords: Silver and chromium nanoparticles, Electrolysis, Electroless deposition, Chemical deposition, Pulse current, Graphite substrate.

\section{1- Introduction}

The process of electroless deposition of silver as affected by galvanic displacement on the semiconducting substrates is a well-known process. This deposition process proceeds via two concurrent electrochemical reactions involving the reduction of metal ions and simultaneous oxidation of the substrate surface. It was reported that a uniform silver film about $50 \mathrm{~nm}$ thick was obtained on a graphite thin sheet (GN) surface via an improved electroless plating method (sun et. al 2008). The authors used 3-aminepropyltrimethoxysilane (APTMS) as an encapsulate to help to limit growth and aggregate formation. Other methods such as electrodeposition (Riccardis 2005), chemical vapour deposition (Yoshinaga et. al 2007) and electrophoretic deposition (Luo et. al 2006) have been claimed for surface metallization of materials. Srikanth et/ al (2009) showed that metallic silver was deposited on the surface of synthesized calcite via a simple electroless deposition method. Calcite with cubic morphology was prepared first by homogeneous precipitation and with subsequent surface modification using ammonium oxalate.

Tang et. al (2007). reported ultrasonic electro-deposition of silver nanoparticles on dielectric silica spheres [6]. The authors showed that silver nanoparticles with sizes of $8-10 \mathrm{~nm}$ in diameter could be homogeneously deposited onto the surface of preformed colloidal silica spheres. Silver particles with different sizes and dispersive uniformity on silica sphere surfaces were obtained by adjusting the current density, the concentration of electrolyte and the electrolysis time. The possible ultrasonic electrodeposition mechanism was also suggested. An electrochemical multiple scan cyclic voltammetry $(C V)$ method (Sondi and Goia 2003) was executed to prepare surface-enhanced Raman scattering (SERS) active silver films, to investigate the effect of potential scan rate and the number of $C V$ scans on the SERS performance. 
Silver nanoparticles was synthesized by the reduction of silver nitrate using a reducing agent of ethylene glycol with polyvinylpyrrolidone. Ethylene glycol containing hydroxyl groups have a functional structure as both solvent and reducing agents. The SERS enhancement capability is particle size and distribution as well surface profile amplitude-dependent with an optimal potential scan rate of $100 \mathrm{mV} / \mathrm{s}$ and $30 \mathrm{CV}$ scans at the experimental conditions used. The highest SERS effect associated with the homogeneously distributed uniform size aggregates merged to interconnecting network as confirmed by scanning electron microscopy and optical profilometry investigation. Rabah (2013) prepared preparation of size-controlled silver nanoparticles on graphite substrate from e-waste. The route involved the extraction of the metals available in nitric acid followed by treatment with hydrofluoric acid. Silver metal particles deposited with an average size of 4-10nm. A stabilizer concentration of 10-40g/ 1 was used. N.V. Mandich (2021) showed that $\mathrm{Cr}^{3+}$ is reduced to chromium metal at $0.74 \mathrm{~V}$. A pulsed electrochemical system was constructed to synthesize size-controllable spherical silver nanoparticles (AgNPs) in the aqueous phase (Wang et. al. 2005, Cuenya, 2010 and Orináková et. al 2013) The circulation system greatly reduces silver deposition rate, thereby making well-dispersed silver nanoparticles colloids to synthesize very conveniently without ultrasonication and string system. Moreover, the particle size of AgNPs was controlled by the experimental parameters (on-time, off-time, and peak current) to improve the homogeneity of the prepared AgNPs. The smallest sized AgNPs with a size of $14.9 \pm 4 \mathrm{~nm}$ were obtained with an on-time, off-time, and peak current of $0.8 \mathrm{~ms}, 0.3 \mathrm{~ms}$, and 0.2 A, respectively. In addition, a clear correlation between the size of silver particles and the peak current was found in that system. Samanta et. al. (2019) studied the deposition mechanism of silver and gold nanoparticles. The authors showed that biomolecular mechanisms deposition of Au and Ag NPs will be helpful for the fabrication of desired shape, size, surface charges and stability. The mechanism of deposition of monolayer nano-silver particles from silver nitrate solution by electroless deposition has also been reported.. The model involves hydration of the metal atoms and diffusion of the hydrated ions from the solution bulk to the cathode vicinity (Cao et. al 2014) in preference to ion discharge (Pilone and Kelsall 2006). The characteristic quality of the product was determined with the XRD, FTIR and SEM measurements Silver first diffuse and deposit in preference to chromium because its ionic size and discharge potential is lower than with chromium (Song et. al 2011, Sun and Xia 2002) Chromium ions then diffuse and deposit on the silver particles, the metal silver is catalytically reactive (Zhu et. al 2000). 
Moreover, it has been shown that the degree of polymerization and concentration of the stabilizing polymer substrate have a marked influence on the size and properties of the deposit the controlling the deposition parameters such as the current density, current-on time, current-off time, duty cycle (ratio of current on time and total pulse time) and pulse frequency.

This study predicts a mechanism model for silver and chromium nanoparticles deposition by electrolysis and electroless methods on a graphite substrate. Influential parameters affect the deposition such as electrolyte concentration, current density, temperature, current on-time, currentoff time, duty cycle (ratio of current on time and total pulse time) and pulse frequency have been studied. The model suggests that silver nanoparticles deposited in preference to chromium on accessible sites of the substrate. Only multiple-layer would take place after satisfying these accessible sites with a silver mono layer

\section{2- Experimental}

\subsection{Materials and Methods}

Pure grade chemicals of Aldrich of silver nitrate, potassium nitrate and potassium hydroxide were used in this work Glassy graphite thin plates having the dimensions 2x10x30 mm and graphitedoped polypropylene sheet $0.3 \mathrm{~mm}$ in thickness were the substrate for silver and chromium deposition. Doubly distilled water was used to prepare the electrolyte.

\subsection{Description of the method for silver and chromium nanoparticles deposition}

Alkaline $0.1 \mathrm{~N}$ silver electrolyte having a $\mathrm{pH}$ value of 8.1 - 10.2 by addition of potassium hydroxide is used. Potassium nitrate solution of $0.05 \mathrm{~N}$ was added as a stabilizing agent. Table 1 shows the conditions of electrodeposition of silver on graphite substrate.

Table (1), Conditions of electro-deposition

\begin{tabular}{|c|c|c|c|}
\hline \multirow[t]{2}{*}{ Parameter } & \multicolumn{3}{|c|}{ Concentration of materials, $\mathrm{g} / \mathrm{l}$} \\
\hline & $\mathrm{Ag} / \mathrm{Cr}$ & $\mathrm{KCN}$ & $\mathrm{KNO}_{3}$ \\
\hline concentration & $0.78 / 0.5$ & 3.02 & $0.1 \mathrm{M}$ \\
\hline $\mathrm{pH}$ & \multicolumn{3}{|l|}{$8.1-10.2$} \\
\hline Time, $t, \mathrm{~s}$ & \multicolumn{3}{|c|}{$2,4,6,12,30,60$ and 120} \\
\hline pulsed current, $t_{\text {on }}$ and $t_{\text {off }}$ & \multicolumn{3}{|l|}{$1(\mathrm{~s})$} \\
\hline Peak current density, $m A / \mathrm{cm}^{2}$ & \multicolumn{3}{|c|}{$0.33,0.45,0.67,1,1.5$} \\
\hline Temperature, ${ }^{\circ} \mathrm{C}$ & \multicolumn{3}{|l|}{$25,50,75$} \\
\hline
\end{tabular}


Table (2) shows the experimental conditions of the work done

\begin{tabular}{|c|c|c|c|c|c|c|}
\hline$N r$. & c. $d$. & $t$ & $p H$ & $t_{o n}$ & $t_{\text {off }}$ & $\begin{array}{l}A \text { (Area of } \\
\left.\text { cathode, } \mathrm{cm}^{2}\right)\end{array}$ \\
\hline 1 & 12 & 2 & 9.1 & 1 & 1 & $1.7-2.7$ \\
\hline 2 & 6 & 2 & 9.1 & 1 & 1 & $1.7-2.7$ \\
\hline 3 & 5 & 2 & 9.1 & 1 & 1 & $1.7-2.7$ \\
\hline 4 & 4 & 2 & 9.1 & 1 & 1 & $1.7-2.7$ \\
\hline 5 & 3 & 2 & 9.1 & 1 & 1 & $1.7-2.7$ \\
\hline 6 & 6 & 4 & 9.1 & 1 & 1 & $1.7-2.7$ \\
\hline 7 & 6 & 8 & 9.1 & 1 & 1 & $1.7-2.7$ \\
\hline 8 & 6 & 12 & 9.1 & 1 & 1 & $1.7-2.7$ \\
\hline 9 & 6 & 16 & 9.1 & 1 & 1 & $1.7-2.7$ \\
\hline 10 & 6 & 20 & 8.3 & 1 & 1 & $1.7-2.7$ \\
\hline 11 & 8 & 2 & 8.3 & 1 & 1 & $1.7-2.7$ \\
\hline 12 & 6 & 2 & 10.3 & 1 & 1 & $1.7-2.7$ \\
\hline
\end{tabular}

\subsection{Deposition of silver with the chemical reduction method}

An impregnating device has been developed. It is composed of a dissector containing a dish filled with silver solution. The dissector led is connected to a vacuum pump fitted with a valve. Graphite cathode were heated at $100-120^{\circ} \mathrm{C}$ outside the dissector and then carefully supported while hot on the edges of silver pot in the dissector. The dissector lid is placed and the vacuum valve is switched on to attain $5 \mathrm{~mm} \mathrm{Hg}$. The graphite sample was kept under vacuum for 30 minutes after which the vacuum valve is closed. The dissector was gently shacked to allow the graphite to fall in the silver pot. The vacuum tap is disconnected to maintain atmospheric pressure. After $1 \mathrm{~h}$, the graphite samples were taken out and dried in a drier. The loaded graphite was immersed in hydrazine hydrate to reduce silver nitrate to yield silver metal. The chemical process of silver deposition can be repeated several times to control the layer thickness of the deposit.

\subsection{Deposition of silver/ chromium with the electrolysis and electroless methods}

An electrolyzing cell was developed to carry out the deposition of silver/ chromium from nitrate electrolyte. The cell is a one compartment box made of Perspex $6 \mathrm{~mm}$ thick. The cell is fitted with cover supporting the anode, the cathode, a separating funnel and a glass stirrer, 
The electrodes were made of graphite-doped polymer sheet $0.3 \mathrm{~mm}$ un thickness connected to the $D C$ main with precise regulator.. Fig. 1 shows a schematic diagram of the electrolysis assembly.

\subsection{Measurements of the physicochemical properties}

Identification and thickness of the deposited silver on the substrate was determined with weight, $\mathrm{X}$ RF and SEM. Phase identification of the ppt metal is performed at room temperature using $\mathrm{X}$ ray diffraction (X RD, Bruker axes $\mathrm{D} 8$, Germany) with $\mathrm{Cu}-\mathrm{K} \alpha(\lambda=1.5406 \AA)$ radiation and secondary mono-chromate in the range $2 \theta$-scale from 20 to 70 degree. The morphology information of the samples such as particle size and particle shape was investigated using transmission electron microscopy TEM with an acceleration voltage up to $120 \mathrm{kV}$, a magnification power up to $600 \mathrm{k}$, and a resolving power down to $0.2 \mathrm{~nm}$ (TEM, JEOL-JEM-1230, Tokyo, Japan). Scanning electron microscope (SEM) JEOL instrument model JSM-5410 was used to determine the microstructure of the deposited silver. The Fourier transform infrared (FT-IR) spectra were recorded on a Jasco FT-IR-3600 pulse

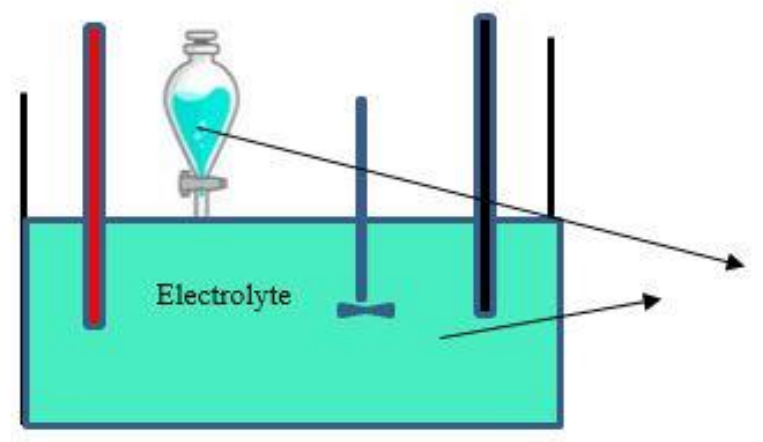

Fig. 1 A schematic diagram of the electrolysis assembly

\section{2- Results}

Table 3 shows the specific rate of silver deposition on graphite substrate

Table (3) the specific deposition rate of silver and chromium on graphite substrate

\begin{tabular}{|l|l|l|l|}
\hline \multicolumn{2}{|l|}{ Sample } & Time, $\boldsymbol{t}$, & Rate of deposition, \\
\hline Nr. & C.d. & $\min$ & $(\mathbf{A g}) \mathbf{m g} / \mathbf{c m}^{2} / \mathbf{m i n}$ \\
\hline 2 & 6 & 2 & 0.217 \\
\hline 3 & 5 & 2 & 0.169 \\
\hline
\end{tabular}




\begin{tabular}{|l|l|l|l|l|}
\hline 6 & 6 & 4 & 0.152 & \\
\hline 8 & 6 & 12 & 0.097 & \\
\hline 9 & 6 & 16 & 0.056 & \\
\hline
\end{tabular}

Fig 3 shows the deposited weight of silver as a function of electrolyte concentration. It is seen that the rate of deposition amounts to $0.515 \mathrm{mg} / \mathrm{cm} 2 / \mathrm{min}$ with $12 \mathrm{~mA} / \mathrm{cm}^{2}$ and decreases to 0.21 and $0.16 \mathrm{mg} / \mathrm{cm}^{2}$ with a current density of 6 and $5 \mathrm{~mA} / \mathrm{cm}^{2}$ respectively

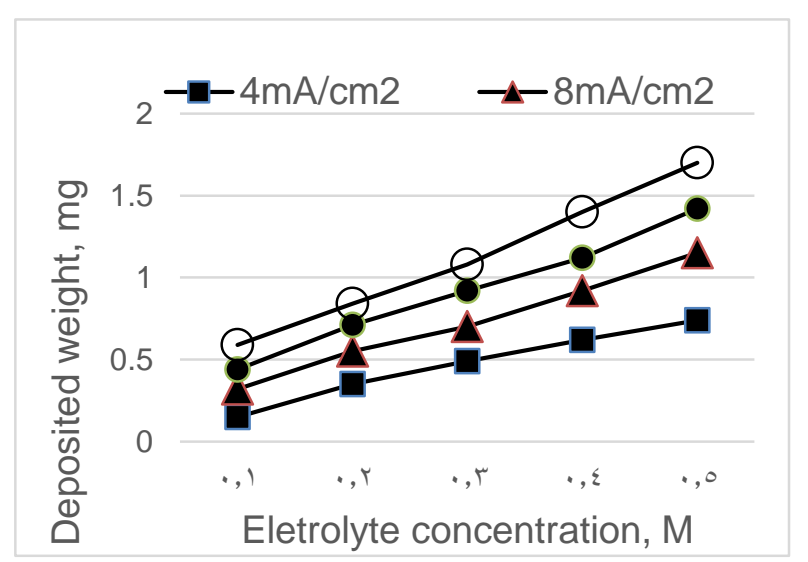

Fig 2 the deposited weight of silver as a function of electrolyte concentration, $\mathrm{pH}=9.1$

Fig. 2 shows the specific rate of deposition of silver metal (d) on graphite. It is seen that $d$ value decreases linearly with time. Figure 4 shows the rate of silver deposition on graphite as a function of time. It is seen that the rate passes through plateau for the first 6 minutes after which it drastically increases to a maximum value at 8 minutes. After which the rate value decreases with further increase in time. It is seen that the rate of weight deposition of the metal ( $\mathrm{Ag}$ or $\mathrm{Cr}$ ) is kept nearly at the same magnitude within the first 5 minutes after which it increases sharply to attain its optimum value with 8 minutes. The extent of the rate of deposition decreases with increasing the time. Fig. 4 shows the effect of temperature on the deposition rate. 


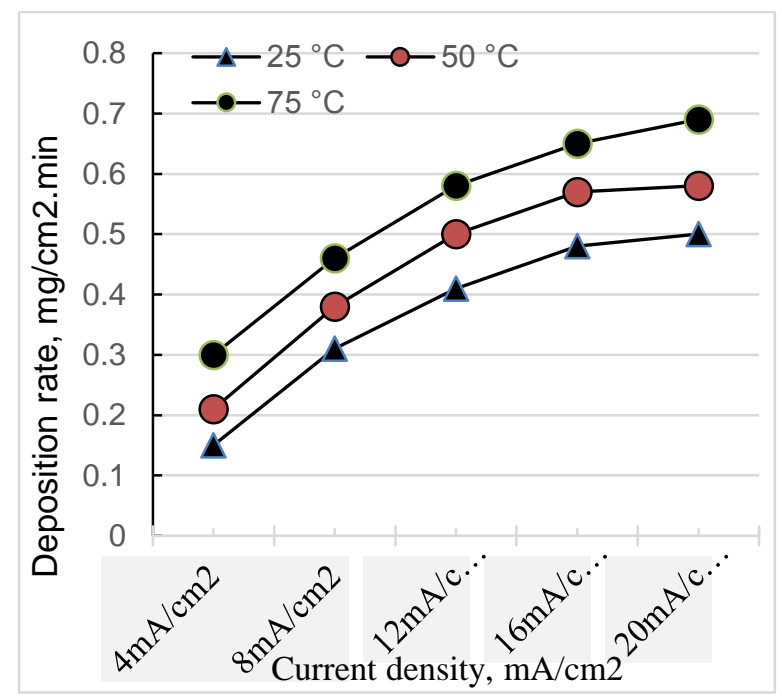

Fig. 3 Effect of temperature on the deposition rate, $\mathrm{pH}=9.1$.

Fig. 4 shows the Arrhenius relation (ln weight deposited of silver against reciprocal absolute temperature, $1 / \mathrm{T} \mathrm{K}$ ), Activation energy $\Delta E$ as calculated amounts to $27.78 \mathrm{~kJ}^{-\mathrm{mol}^{-1}}$. $\mathrm{K}$ and 27.220 $\mathrm{kJ} . \mathrm{mol}^{-1}$. K with silver and chromium respectively.

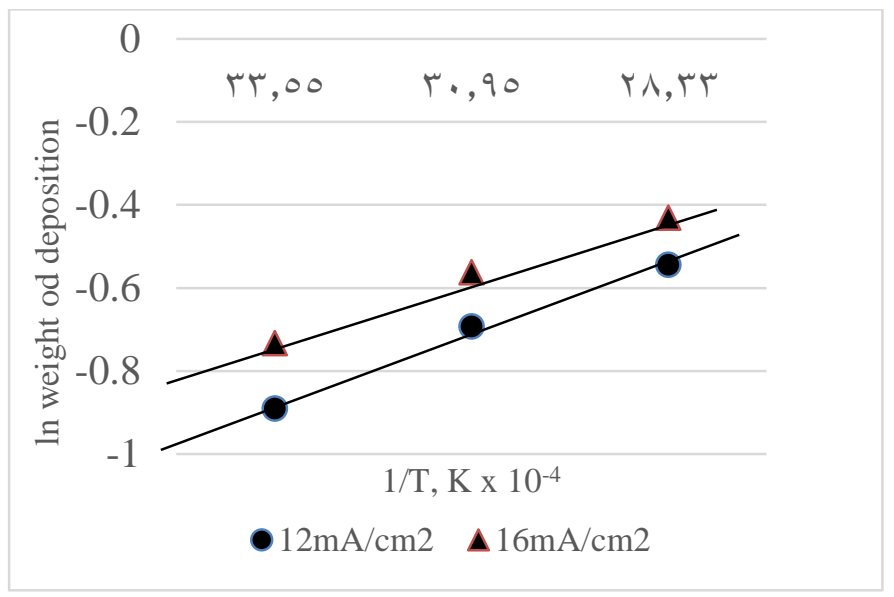

Fig. 4 the Arrhenius relation (in weight deposited vs $1 / T, K x 10^{-4}, \mathrm{pH} 9.1$.

Fig. 5 shows the cyclic Volta-monogram of $\mathrm{Ag} / \mathrm{C}$ electrode in $0.1 \mathrm{M} \mathrm{KOH}$ and $0.1 \mathrm{KOH}+0.2$ $\mathrm{M}$ ethanol, 0.5 Meth, 1.0 M ethanol at a scan rate of $5 \mathrm{mV} \mathrm{s}^{-1}$. It can be seen that current density is kept more or less the same magnitude up to a scan rate value of $0.4 \mathrm{mV}$. With higher scan rate $>0.6 \mathrm{mV}$, the current density increases drastically and such increase becomes pronounced the general trend of the results indicate that the scan rate has no effect on the current density (I, mA/an ${ }^{2}$ ) up to $9 \mathrm{mV}$. 
Increasing the scan rate $>9 \mathrm{mV}$ and addition of ethyl alcohol to $1 \mathrm{M} \mathrm{KOH}$ alkaline electrolyte strongly increases the current density to about $10.4 \mathrm{~mA} / \mathrm{cm}^{2}$ with $2 \mathrm{M}$ alcohol. It is worth noting that with higher alcohol up to $5 \mathrm{M}$ has a pronounced decrease in the current density to 8 $\mathrm{mA} / \mathrm{cm}^{2} \cdot$ with $+1.0 \mathrm{~V}$,

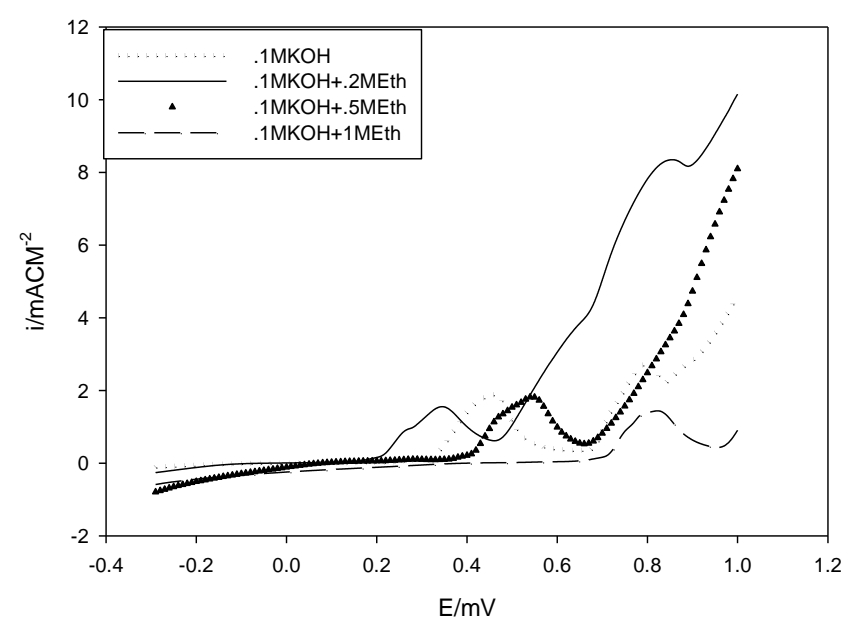

Fig.5 Cyclic Volta monograms of $\mathrm{Ag} / \mathrm{C}$ electrode in $0.1 \mathrm{M} \mathrm{KOH}$ and $0.1 \mathrm{KOH}+0.2 \mathrm{Meth}, 0.5$ Meth, 1.0 Meth at a scan rate of $5 \mathrm{mV} \mathrm{s}^{-1}, \mathrm{pH} 10$

Fig. 6 shows the effect of scan rate on the pulse current value at a scan rate of $5 \mathrm{mV} / \mathrm{s}-100 \mathrm{mV} / \mathrm{s}$. It is seen that the early low scan rate from -0.6 up to $+0.2 \mathrm{mV}$ has no significant effect on the current density. With further increase of the scan rate, a marked increase of the current density takes place passing through a maxima with $0.5 \mathrm{mV}$ and that effect is directly related to the scan rate.

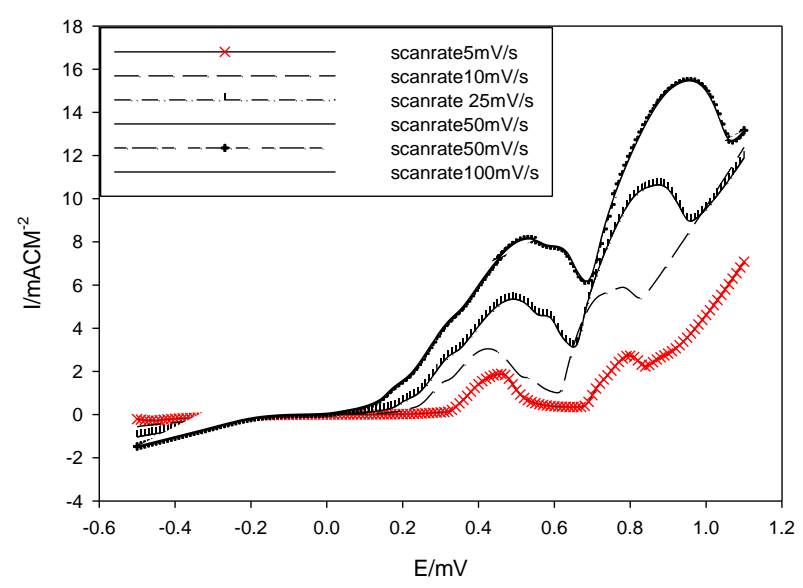

Fig. 6 Effect of potential on the pulse current density at different scan rate, $\mathrm{pH}=10$ 
Figure 7 shows the relationship of potential against current $\mathrm{i} \mathrm{E}(\mathrm{mv}) / \mathrm{i}$ at a scan rate of $5 \mathrm{mV} / \mathrm{s}$ in alkaline medium as affected by addition of potassium hydroxide together with methyl alcohol. It can be seen that alkalinity suppress the change in pulse current $(\leq 1 \mathrm{mV})$ with increase in potential up to $0.5 \mathrm{mV}$. The current density value drastically increases $\left(10 \mathrm{~mA} / \mathrm{cm}^{2}\right)$ with further increase in potential up to $0.8 \mathrm{mV}$.

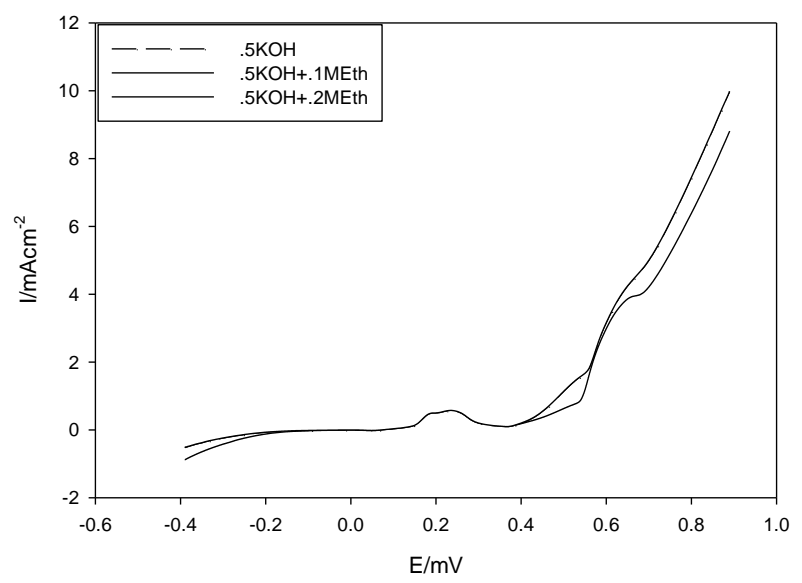

Fig. $7 \mathrm{E} / \mathrm{i}$ relation as affected by the addition of $\mathrm{KOH} / \mathrm{methyl}$ alcohol using $5 \mathrm{mV}$ scan rate, $\mathrm{pH}=10$

\section{5- Discussion}

Electrodeposition implies the deposition of a solid metal from a solution of soluble molecules, ions or complexes by the action of electricity.

Because the electrodeposition process of silver nanoparticles is of special interest because nanoparticles may display a high decorative activity. The parameters determining the qualitative and quantitative deposition of silver on a graphite substrate has been literature (Yin et. al 2020). In that work, silver nanoparticles are deposited applying moderate current density from silver electrolyte. Results given in Fig. 3 proved that the deposition rate increases with increase of current density and temperature in a regular relation. The deposition process takes place in successive steps as follows.

a. silver Ionic radius amounts to $1.15 \ddot{\mathrm{A}}(+1)$ (ChemGlob eriodic Table 2021) the metal. Ion (available in the electrolyte) is firstly hydrated. The hydrate is defined as an inorganic salt containing water molecules combined in a definite ratio either bound to a metal center or have crystallized with the metal complex to $\left[\mathrm{M}\left(\mathrm{H}_{2} \mathrm{O}\right) \mathrm{n}\right]^{\mathrm{z}+}$. 


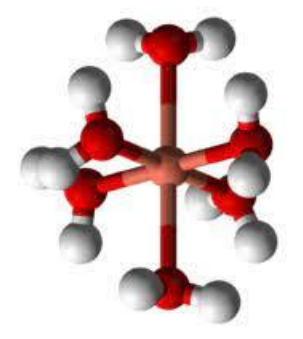

A model of hydrated metal

$$
\mathrm{M}^{+}+\mathrm{nH}_{2} \mathrm{O}
$$

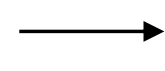

$\left.\mathrm{M}\left(\mathrm{H}_{2} \mathrm{O}\right) \times{ }^{\times}\right] \times+$

b. under the potential difference between the positive and negative electrodes, the charged metal ions diffuse from the solution bulk to the cathode vicinity. Diffusion enhances with temperature rise.

c. the diffusing ions then penetrate the boundary layer of the cathode and adhere to the charged cathode surface whereby it get reduced to a metal nanoparticle.

The regular relation given in Fig. 3 shows that step (b) is the rate-determining step. Fig. 5 supports this assumption. The rate of deposition is low within the early period of deposition and increases up to $6 \mathrm{~min}$ to $9 \mathrm{~min}$. With time $>9 \mathrm{~min}$, the rate of deposition decreases on the bases that the ions concentration in the electrolyte gradually deplete despite stirring. Fig. 4 shows the Arrhenius plot of the electrodeposition process with silver. The computed $\Delta \mathrm{E}$ value amounts to $27.78 \mathrm{~kJ}^{\mathrm{mol}}{ }^{-}$ ${ }^{1} . \mathrm{K}$ and $27.220 . \mathrm{kJ} \mathrm{mol}^{-1}$. with $12 \mathrm{~mA} / \mathrm{cm}^{2}$ and $16 \mathrm{~mA} / \mathrm{cm}^{2}$ respectively. The metal silver's reactivity may be proportional to the size and shape of the metal nanoparticles. With silver, the atomic volume is $10.28 \mathrm{~cm}^{3} / \mathrm{mol}$ [21].

Ionic silver is a solution consisting of water and silver ions (dissolved silver) containing no silver particles Ionic silver is up to $10^{4}$ times more effective than colloidal silver. The ionic radius of silver is $1 \times 10^{-12}$ meter $\left(1 \times 10^{-3} \mathrm{~nm}\right)$.

The regular relation holding the deposited weight and electrolyte concentration given in Fig. 2 shows that step (b) is the rate-determining step. Fig. 3 supports this assumption. The rate of deposition is low within the early period of deposition and increases after 6 min - 9 min. With time $>9$ min, the rate of deposition begins decreasing on the bases that the ion concentration in the electrolyte gradually deplete despite stirring and for this reason the experimental electrodeposition cell is fitted with a separating funnel filled with a freshly prepared silver nitrate solution. 
The tap of the funnel is accurately adjusted to compensate the continuous loss of the discharging silver ions and keep the electrolyte concentration at more or less constant value. Fig. 4 shows the Arrhenius plot of the electrodeposition process with silver. The computed $\Delta \mathrm{E}$ value amounts to $27.78 \mathrm{~kJ} \cdot \mathrm{mol}^{-1} \cdot \mathrm{K}$. That shows that silver is reactive metal ions. The reactivity seems to be proportional to the size and shape of the metal involved. With silver, the atomic volume is 10.28 $\mathrm{cm}^{3} / \mathrm{mol}$ (SchoolMyKids.com 2021). In this context, the current density directly relates to the amount of the deposited metal. That proposal is because current supply of electrons to the electrolyte via the cathode surface would increase in the potential and enhance step (b) to take place. Addition of alcohol to the metal ions will squash the deposition process. Fig. 9 shows image of SEM of the deposited silver (a), silver with alcohol at $12 \mathrm{~mA} / \mathrm{cm}^{2}$ (b) and $16 \mathrm{~mA} / \mathrm{cm}^{2}$ (c)
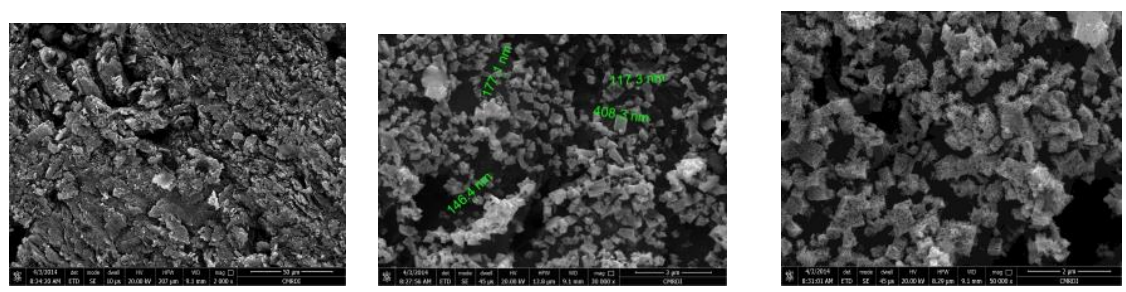

Fig. 8 (a) Ag, 12 mA/cm² Fig. 8 (b), Ag + alcohol Fig. 8 (c) $\mathrm{Ag} 16 \mathrm{~mA} / \mathrm{cm}$

Fig/ 8 SEM images of deposdited silver

Fig. 9 shows the XRD of the deposited silver nanoparticles by pulse current.

Sharp peaks of the XRD pattern, appeared at $2 \theta$ of $28,34,38,48$, explore the material is crystalline. Whereby the peaks are distinctive to silver. Fig. 10 shows the FT-IR of silver.

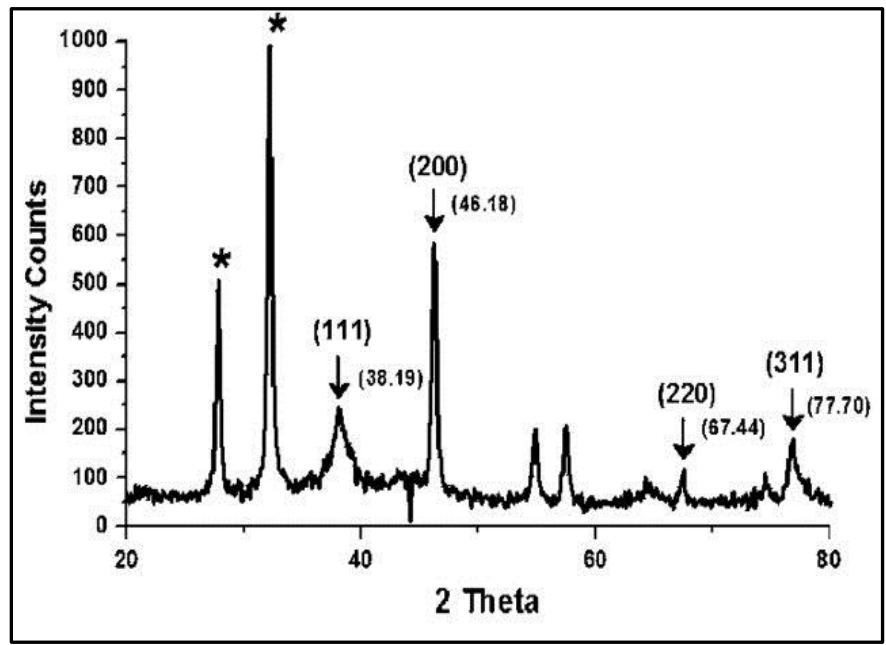

Fig. 9 XRD pattern of the silver nanoparticles deposited by pulse current. 


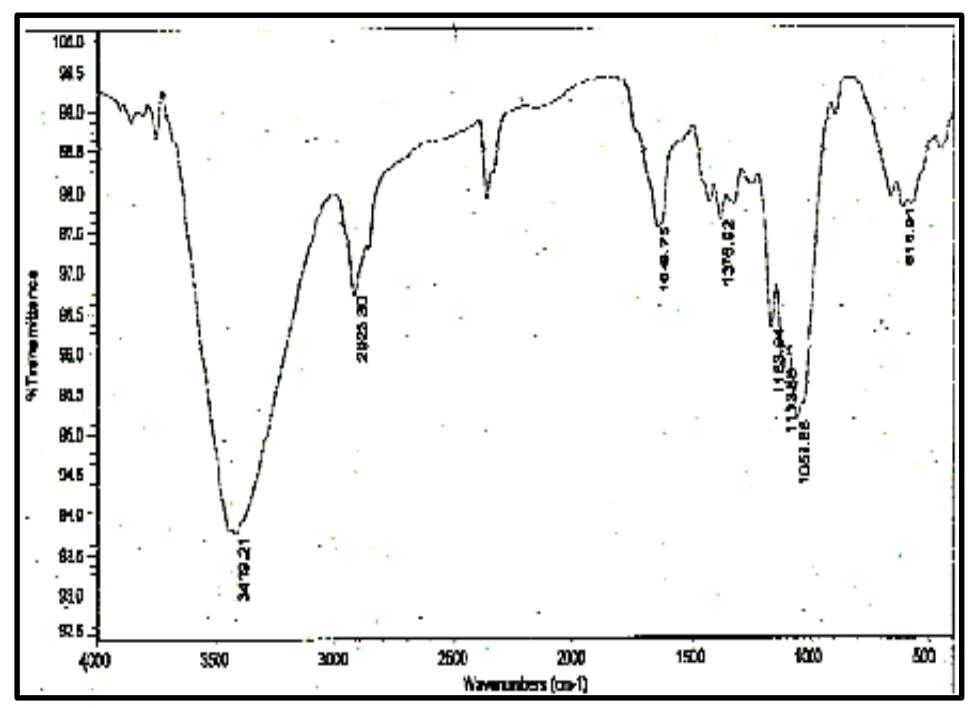

Fig. 10 a FT-IR of silver nanoparticles

\section{6- Conclusion}

Electrodeposition of silver nanoparticles exhibit a wide scope of applications in the fields of energy, environmental, and medical technologies because of its unique properties determined primarily by their size, composition, and structure. Silver nanoparticles have been of interest because of their unusual and fascinating properties. The electrolyte conditions are nitrate solution with low concentration controlled by the addition of potassium nitrate and potassium cyanide as a stabilizer. The electrolyte was a $0.01 \mathrm{M}$ solution of pure silver nitrate using an electrolyzing cell. EDC with current density up to $20 \mathrm{~mA} / \mathrm{cm} 2$ and $15 \mathrm{mV}$ and pulse current showed that silver deposited at a rate of $0.515 \mathrm{mg} / \mathrm{cm}^{2} / \mathrm{min}$ with $12 \mathrm{~mA} / \mathrm{cm} 2$ and decreases to 0.21 and $0.16 \mathrm{mg} / \mathrm{cm} 2 . \mathrm{min}$ with the decrease of current density to 6 and $5 \mathrm{~mA} / \mathrm{cm} 2$ respectively. A mechanism of deposition postulates that such mechanism is a multi-sequence process. Silver deposited in reference to the discharge potential of silver is low $(0.38 \mathrm{mV})$ as compared to other metals (e.g. $0.82 \mathrm{mV}$ with chromium). Pulse current controls silver deposition due to flexibility in controlling one or more of the deposition-steps involved. The optimum electrodeposition conditions for silver in nano size are current density $=6 \mathrm{Adm}^{-2}, \mathrm{pH} 9.1$, silver concentration 0.04 $\mathrm{N}$, pulse ton $=\mathrm{t}$, off $=1$ at room temperature. Nanoparticles of silver deposited successfully on graphite substrate and their catalytic activity increases when porous graphite demonstrated as a substrate. Pulse current helps to deposit silver in nano-size particles from silver nitrate at alkaline $\mathrm{pH}$ value. 


\section{7- Conflict of Interest}

We here confirm

o The authors have participated in (a) conception and design, or analysis and interpretation of the data; (b) drafting the article and (c) approval of the final version.

o This manuscript has not been submitted to, nor is under review at, another journal or other publishing venue.

o The authors have no affiliation with any organization with a direct or indirect financial interest in the subject matter discussed in the manuscript

o The following authors have affiliations with CMRDI organization with direct or indirect financial interest in the subject matter discussed in the manuscript:

o The submission has no financial interest from anywhere. No funds or other support was received. The authors have no relevant financial or non-financial interest to disclose. The authors certify that they have no conflict of interest that are relevant to the content of the submitted article and they have no affiliations with in any organization or involvement in the subject matter or any material discussed in this article.

\section{8- Reference}

Sun, W. Chen G. and Zheng, L. (2008) Electroless deposition of silver particles on graphite nanosheets Scripta Materialia 59(10), November 2008, 1031-1034

Riccardis, M. D. Graphite Appl. Surf. Sci., 252 (2006), p. 5403

Yoshinaga, H. Takahashi, K. Yamamoto, A. Muramatsu, T. MorikawaJ. Colloid Interf. Sci., 309 (2007), p. 149.

Luo, K. Shi, N. L. Cong, H.T. and Sun, C. (2006) J. Solid State Electron., 10 (2006), p. 1003. 
Srikanth C. K. .Jeevanandam, J. (2009) "Electroless deposition of silver on synthesized calcite via surface modification" Applied Surface Science 255(16), 30 May 2009, 7153-7157

Tang Sh., Tang Yu., Gao F., Liu Zh. and Meng Xi (2007) "Ultrasonic electro-deposition of silver nanoparticles on dielectric silica spheres" Nanotechnology Volume 18 Number 29 doi:10.1088/0957-4484/18/29/295607

Sondi, D.V and. Goia, E. (2003) Matijevć, J. Colloid Interface Sci. 260, 75

Rabah, M.A. (2013) "Preparation of size controlled silver nanoparticles from E-waste by electrokinetic and chemical and electrokinetic processes", International J. Chemical materials Science and Engineering, 7 (8), 75-80

Mandich N.V. (2021) "Chemistry \& Theory of Chromium Deposition: Part I - Chemistry" Plating and surfac e finishing,

Wang, D., Song, C., Hu Z. and Zhou_X. (2005) Synthesis of silver nanoparticles with flakelike shapes”. Materials letters, Vol. 59(14-15\}1760-1763,

Cuenya, B/R. (2010) Synthesis and catalytic properties of metal nanoparticles: size, shape, support, composition, and oxidation state effects Thin Solid Films, 518 pp. 3127-3150.

Orináková' R., Škantárová, L., Orinák, A., Kupková D .J. and Andersson J. T., (2013) "Electrochemical deposition of SERS active nanostructured silver films", Int. J. Electrochem. Sci., 8, $80-99$.

Samanta S., Agarwal Sh. KishoreNair K., Richard A, Harris A and Swart H. (2019) "Biomolecular assisted synthesis and mechanism of silver and gold nanoparticles" Materials Research Express, Volume 6, (8)

Cao B. J., Li; Z. Zhong-Dong C., Hai-Yan H., Xiang X., Li, W. and Gao-Rong H. (2014) "Electrodeposition of silver nanoparticle arrays on ITO coated glass and their application as reproducible surface-enhanced Raman scattering substrate" Applied Surface Science, Volume 258, Issue 5, p. 1831-1835. 
Pilone D. and Kelsall G.H., (2006) "Prediction and measurement of multi-metal electro deposition rates and efficiencies in aqueous acidic chloride media", Electrochim. Acta, 5, $3802-3808$,

Song, X. P. Gunawan, R. Jiang, S. Leong S.J., Wang, K. and Xu R., (2011) “Surface activated graphite nanospheres for fast adsorption of silver ions from aqueous solutions, J. Hazard. Mater. Vol., 194, 162-168,

Sun, Y and Xia Y. (2002) "Shape-controlled synthesis of gold and silver nanoparticles" Science, 298 pp. 2176-2179,.

Zhu J. Liu S., Palchik O., Koltypin Y., and Gedanken A. (2000) "Shape-Controlled Synthesis of Silver Nanoparticles by Pulse Sonoelectrochemical Methods", Langmuir, 16, 6396-6399

Yin D., Liu Y., Chen P., Meng G. , Huang G. , Cai, 1 L. and Zhang L., (2020) "Controllable Synthesis of Silver Nanoparticles by the Pulsed Electrochemical Deposition in a Forced circulation Reactor" Int. J. Electrochem. Sci., 15 (2020) 3469 - 3478, doi: $10.20964 / 2020.04 .57$

ChemGlob eriodic Table of the Elements, Physucal data. Internet (2021_.

SchoolMyKids.com (2021) "Periodic Table Element Comparison: Compare Elements - Silver vs Chromium" 2021 internet.

Copyright ( 92022 Prof. Dr. Mahmoud A. Rabah, Prof. Dr. Nabil Nassif Girgis, AJRSP. This is an Open-Access Article Distributed under the Terms of the Creative Commons Attribution License (CC BY NC)

Doi: https://doi.org/10.52132/Ajrsp.e.2022.33.1 